\title{
The Effect of Using Small-Sided Games on Developing the Skill Performance Level of Advanced Football Course Students at Mutah University
}

\author{
Esam Najeh Abu-Shihab \\ Faculty of Sport Sciences, Mutah University, Jordan \\ Received February 5, 2021; Revised March 26, 2021; Accepted April 18, 2021
}

\section{Cite This Paper in the following Citation Styles}

(a): [1] Esam Najeh Abu-Shihab, "The Effect of Using Small-Sided Games on Developing the Skill Performance Level of Advanced Football Course Students at Mutah University," International Journal of Human Movement and Sports Sciences, Vol. 9, No. 3, pp. 451 - 460, 2021. DOI: 10.13189/saj.2021.090309.

(b): Esam Najeh Abu-Shihab (2021). The Effect of Using Small-Sided Games on Developing the Skill Performance Level of Advanced Football Course Students at Mutah University. International Journal of Human Movement and Sports Sciences, 9(3), 451 - 460. DOI: 10.13189/saj.2021.090309.

Copyright $\bigcirc 2021$ by authors, all rights reserved. Authors agree that this article remains permanently open access under the terms of the Creative Commons Attribution License 4.0 International License

\begin{abstract}
The small-sided games are widely used by coaches to develop physical abilities, technical and tactical skills. This study aimed at investigating the effect of using small-sided games on developing the level of skillful performance of students of an advanced football course at Mutah University. The study sample consisted of 28 students of both genders, which were chosen from an advanced football course at Mutah University and were divided into two groups (14 each). The experimental approach was applied, while "t-test" was used to detect the differences between the control and the experimental and to detect the differences between the members of the two groups at the post application stage. The results showed statistically significant differences at the level of significance $(\alpha \leq 0.05)$ in the Pre- and post-measurements of the effect of using small-sided games on developing abilities and the skill level. And statistically significant differences were detected for the benefit of post measurement for students of an advanced football course. The results also showed that there were statistically significant differences at the significance level $(\alpha \leq 0.05)$ in the Post measurement, between the use of small-sided games and the regular training in developing the level of skill performance, and for the benefit of the small-sided games for students of an advanced football course. The researcher recommended the importance of making use of the small-sided games program to developing the level of skillful performance of students in football courses, in all
\end{abstract}

departments and colleges of Physical Education and for both genders in Jordan.

Keywords Small-Sided Games, Skill Performance Level, Students of an Advanced Football Course

\section{Introduction}

In the recent period, it has been noticed the extent of the development in the game of football in various fields and sports training in terms of training methods, tools used and high technical level, Football game became a product of scientific research in this field and a demand of all countries of the world. This in turn contributed to the development of coaches all over the world for gaining better achievements and global reach (Al-Khatib, 2010). However, Tchokonte's (2011) study goes with this alignment, which confirmed that in recent decades football has witnessed changes in all physical, artistic, tactical and psychological aspects, and these changes have been effective for improving sports performance. Dellal et al. (2011) added that the intensity exerted in competition resulted in changes in the methods and training tools, and it was approved by recent studies which revealed that the modern training has been directed towards the integration of physical, technical, tactical and psychological 
characteristics. Chebbi (2016) argued that modern sports training made a great leap in the development of all physical, skill, planning and cognitive aspects of the players. In the annual program of training, lots of work was devoted to training players on methods using small-sided games in all stages. While (Hill-Haas et al.2011) added that small-sided games are popular in improving fitness and technical skills simultaneously. Dellal et al. (2012) indicate that numerous European schools and academies use small-sided games in training to develop playing methods and plans depending on age. Giving it more time in the daily units, those European schools and academies consider small-sided games as an essential part of the training unit. Coaches use small -games to create situations similar to the match to develop the schematic aspects of young players, Owen. Twist. and Ford. (2004) added, through the small-sided games players face situations similar to those they do in competitive matches. Katis and Kellis (2009) indicated that small-sided games are very popular not only with big football players but also among young players as their use begins at an early age due to small fields and a small number of participants When matches on small spaces, each player is in contact with the ball, and often looking at common game situations that require good skills of passing, dribbling, and hitting the ball. In addition to tactics such as running without the ball, getting rid of observation, and cooperating with other players. Taha and Jalal (2019) confirm that small-sided games are played by all age groups because of its apparent effect on developing and improving the technical performance of the players, where player becomes skilled due to the large number of ball touches during matches. Thus, that mini-matches which are held with fewer players in the official competition leads to quick decision-making during the course of matches, which leads to the development of tactical aspects. Hassan and Hisham (2014) add that the small-sided games occupy a prominent place in the plans to learn and develop basic skills for the first stage of football. As they develop the physical capabilities of the players as well as mental abilities. They are considered one of the most important methods in helping trainers facilitating their training tasks. These results were agreed by (Jones and Drust. 2007), who indicated that the small-sided games are widely used by coaches to develop technical and tactical skills. And it is consistent with Yaseen (2016) study as well, in that small-sided games training resembles real situation exercises during actual matches, plus raises the level of training aimed at developing and stabilizing basic skills in football. However, Dellal, et. al, (2008) indicate that the small-sided games are programming exercises using the ball in different settings and rules set by the coach, as they differ according to the different training objectives. Little (2009) decide that the only differences that distinguish small-sided games are the less players and the less playing space or sometimes adding or modifying certain rules. Abu Abdo (2007) asserts that basic skills are among the most important technical aspects in football activity and without the perfect performance or less mastery, the player cannot follow the coach's instructions, especially the tactical aspect. Football is characterized by the abundance and diversity in its basic skills. The level of performance of football has increased in line with the development the playing methods and the diversity of defensive and offensive plans. All of that requires a distinguished and optimal performance of the basic skills of football.

\section{Problem and Importance of the Study}

Through the scientific and practical experience of the researcher as a current football courses teacher and a former football player and coach, and by reviewing the previous studies, scientific research and curricula applied in soccer competitions, the researcher noted that the football curricula taught in the Jordanian universities is partially insufficient in the field of training and in educational programs. Which is incommensurate with the abilities and skills of students of physical education colleges. The researcher also noted that teachers of these courses use regular and non-modern methods, and have lack of interest in applying the up-to-date scientific approaches, such as small-sided games, which are of great importance in physical preparation, skills and plans in football. Performing small-sided games, students are more in touch with the ball where the space used decreases the number of players inevitably, which in turn develop and improve the level of performance of the players and the game as a whole, especially when determining the goal of the game. The researcher points out that the importance of these small-sided games lies in being appropriate environment for football players and all age groups and students of football courses at universities. Adding to that, its role in placing the player in settings similar to the actual competitive matches. Small-sided games are characterized by performing a physical technical effort and high intensity plans for a long period of time, the performance of which requires the physical, motor and skill adaptations.

\section{Study Objectives}

This study aimed at identifying the following:

1. The effect of using small-sided games on developing the level of skill performance of students of an advanced football course at Mutah University.

2. The effect of using regular training on developing the level of skill performance of students of an advanced football course at Mutah University.

3. The difference between the effect of using small-sided games and regular training on developing the skill level of students of an advanced football course at the University of Mutah. 


\section{Study Hypotheses}

This study sought to answer the following hypotheses:

1. There are statistically significant differences at the level of significance $(\alpha \leq 0.05)$ between the pre and post measurements of the effect of using small-sided games on developing the level of skill performance and for the benefit of post-measurement of students of an advanced football course at Mutah University.

2. There are statistically significant differences at the level of significance $(\alpha \leq 0.05)$ between the pre and post measurements of the effect of regular training on developing the level of skill performance and in favor of the post measurement of students of an advanced football course at Mutah University.

3. There are statistically significant differences at the significance level $(\alpha \leq 0.05)$ in the telemetry between the use of small-sided games and the regular training on improving the performance level of students of an advanced football course at the University of Mutah?.

\section{Limitations of the Study}

*Spatial determinant: Stadium of the College of Sports Sciences (Khalid bin Al-Walid), Mutah University, Karak.

*Timeline: This study was conducted during the period 10/18 - 12/12/2020.

*The human determinant: 28 students of an advanced football course of the Faculty of Sports Sciences at the University of Mutah.

*Technical determinant: The proposed training program of this study (small-sided games for the experimental sample), (and the normal training program of the control sample), Appendix (A) clarifies that.

\section{Research Methodology and Procedures}

Study methodology: In line with the type and objectives of the study, the researcher used the semi-experimental method, using the experimental and control groups with two measurements, pre and post.

Study population and its sample: The study population consisted of the whole students of the advanced football course (specialization) of the first semester of the academic year 2020/2021 AD, which were (28) students. Thus, the study community is its sample members, and were subject to it.

Equivalence of study groups: To verify the parity of the two groups (control and experimental) before starting the application process, a "t-test" was conducted for the independent samples (Independent Samples Statistics). It was applied to reveal the parity in the pre-measurement of the skill level of students in an advanced football course according to the group variable as shown in Table 1.

The data in Table 1 show that there are no statistically significant differences at the level of significance $(\alpha \leq 0.05)$ in the pre-measurement of the level of skill performance of the football beginners according to the group variable, which indicates the parity of members of the two groups before starting the application process.

Table 1. "t-test" for independent samples to verify the equivalence of groups in the prior application of the level of skill performance (N=28)

\begin{tabular}{|c|c|c|c|c|c|c|c|c|}
\hline $\begin{array}{c}\text { Football } \\
\text { skills }\end{array}$ & Test & $\begin{array}{c}\text { Measure } \\
\text { unit }\end{array}$ & Group & $\begin{array}{c}\text { arithmetic } \\
\text { mean }\end{array}$ & $\begin{array}{l}\text { standard } \\
\text { deviation }\end{array}$ & $\begin{array}{c}\text { Freedom } \\
\text { degree }\end{array}$ & T value & $\begin{array}{c}\text { Statistical } \\
\text { significance }\end{array}$ \\
\hline \multirow{2}{*}{$\begin{array}{c}\text { Feeling and } \\
\text { control the } \\
\text { ball }\end{array}$} & \multirow{2}{*}{$\begin{array}{l}\text { Dribbling } \\
\text { the ball }\end{array}$} & \multirow[b]{2}{*}{ Repetition } & Experimental & 53.61 & 12.60 & \multirow[b]{2}{*}{26} & \multirow[b]{2}{*}{1.96} & \multirow[b]{2}{*}{$0.620 \%$} \\
\hline & & & Control & 52.10 & 9.78 & & & \\
\hline \multirow{2}{*}{$\begin{array}{l}\text { Running } \\
\text { with the } \\
\text { ball }\end{array}$} & Running & \multirow[b]{2}{*}{ Time/s } & Experimental & 8.56 & 0.36 & \multirow[b]{2}{*}{26} & \multirow[b]{2}{*}{1.75} & \multirow[b]{2}{*}{$0.498 \%$} \\
\hline & $\begin{array}{l}\text { with the } \\
\text { ball } 30 \mathrm{~m}\end{array}$ & & Control & 8.75 & 1.11 & & & \\
\hline \multirow[b]{2}{*}{ Passing } & Passing & \multirow[b]{2}{*}{ Degree } & Experimental & 1.36 & 1.26 & \multirow[b]{2}{*}{26} & \multirow[b]{2}{*}{0.87} & \multirow[b]{2}{*}{$0.336 \%$} \\
\hline & $\begin{array}{l}\text { accuracy } \\
\text { test } 4 \text { goals }\end{array}$ & & Control & 1.52 & 1.56 & & & \\
\hline \multirow{2}{*}{ Dribbling } & Slalom Run & \multirow{2}{*}{ Time/s } & Experimental & 12.02 & 0.72 & \multirow{2}{*}{26} & \multirow{2}{*}{2.25} & \multirow{2}{*}{$0.273 \%$} \\
\hline & $25 \mathrm{~m}$ & & Control & 12.13 & 0.73 & & & \\
\hline \multirow[b]{2}{*}{ Shooting } & Shooting & \multirow[b]{2}{*}{ Degree } & Experimental & 2.32 & 0.59 & \multirow[b]{2}{*}{26} & \multirow[b]{2}{*}{0.59} & \multirow[b]{2}{*}{$0.523 \%$} \\
\hline & $\begin{array}{l}\text { the ball } \\
\text { from } 5 \\
\text { sections }\end{array}$ & & Control & 2.45 & 0.84 & & & \\
\hline
\end{tabular}

* Statistical function at the level of significance $(\alpha \leq 0.05)$

Table 2. "t-test" for independent samples to verify the equivalence of groups according to a variable (age, weight, height) (N=28)

\begin{tabular}{cccccc}
\hline variable & Group & $\begin{array}{c}\text { arithmetic } \\
\text { mean }\end{array}$ & $\begin{array}{c}\text { standard } \\
\text { deviation }\end{array}$ & $\begin{array}{c}\text { Freedom } \\
\text { degree }\end{array}$ & T value \\
\hline \multirow{2}{*}{ Age/year } & Experimental & 20.93 & 0.56 & 26 & 0.379 \\
& Control & 20.80 & 0.61 & 3.76 & 26 \\
Weight $/ \mathrm{kg}$ & Experimental & 75.80 & 2.18 & 0.73 \\
& Control & 76.90 & 4.61 & 26 & 0.801 \\
Height $/ \mathrm{cm}$ & Experimental & 174.67 & 4.03 & 0.430 \\
\hline
\end{tabular}


The process of verifying the equivalence of the two groups in each of the variables (age, weight, height) and Table 2. illustrate the results of that.

The data in Table 2. display that there are no statistically significant differences at the level of significance $(\alpha \leq 0.05)$ in the variables (age, weight, height) according to the group variable, which indicates the parity of the members of the two groups.

\section{Scientific Transactions for the Study Tests}

First: Certification of tests: The researcher presented the study tests to a number of specialized referees and experts in order to ascertain the purpose of these tests and their suitability to measure the study variables, After review and judgment by experts, adjustments have been made according to the observations of the arbitrators, and tests that were unanimously agreed upon -with a percentage of not less than $(80 \%)$ of the arbitrators- were adopted. Appendix (C) shows the arbitrators' list, indicate their profession, academic position, and qualifications.

Second: Stability of tests: Verifying the stability of the study tests, the researcher applied the tests to an exploratory sample of (3) students from the study community and was excluded from the sample. The tests were re-applied after (2) two days from the first application. Accordingly, Pearson correlation revealed a coefficient between the two tests, which indicates a stability of the measurements. Table No. (3) illustrates the results.

Table 3. Pearson correlation coefficient between the two applications as an indicator of the stability of the study tests

\begin{tabular}{cc}
\hline Tests & Stability coefficient \\
\hline Dribbling the ball & 0.85 \\
Running with the ball (30) $\mathrm{m}$ & 0.83 \\
Passing accuracy (4) goals & 0.80 \\
Slalom running (25) $\mathrm{m}$ & 0.81 \\
Shooting the ball from (5) sections & 0.82 \\
\hline
\end{tabular}

Table 3. reveals that the test reliability coefficients ranged between (0.80-0.85), and such values are considered acceptable for the purposes of the current study.

\section{Study Implementation Procedures:}

The study implementation procedures were divided according to the following:

First: Pre-tests for the level of skill performance:

After conducting the exploratory study and verifying the validity and reliability of these tests, the researcher conducted pre-tests on the study sample, in the period between $(13-15 / 10 / 2020)$.

Second: Implementing the training program for the experimental group using the small-sided games and the usual training for the control group that was previously prepared:

After ascertaining the parity of the sample in the pre-tests of the level of skill performance, and the equivalence of the variables of age, height and weight, the training program was applied by using small-sided games on the members of the experimental group. Where the researcher prepared a training program using small-sided games, relying on his field experience and drawing on the opinions of specialists in the field of sports training science and specialized scientific sources and research in football training programs. Which is usually taught for advanced football courses. This regular training program which was prepared in advance by the researcher was applied on the control group. The training program was applied on the two groups and was divided as (24) training units, each of which was (90) minutes long, including the introductory and final stages. The time in the main section ranges from (40-60) minutes, according to the goal of each training unit. These units contained a set of exercises, small-sided games for the experimental group and the usual exercises for the control group, which aims at preparing the players in terms of skill, which reached (75) -95\%) of the student's maximum ability. Accordingly, the execution of the training units took (8) weeks by (3) training sessions per week (Sunday, Tuesday, and Thursday) at the stadium of the College of Sports Sciences (Khalid bin Al-Walid). It started from the first week 10/18 - 12/12/2020.

Third: Post-tests for the level of skill performance:

After applying the training program to the members of the experimental group using the small-sided games and the regular training program for the control group, the researcher conducted the post tests on the date (14-16 / 12/2020). The tests were conducted with the same conditions and standards and with the same field where the Pre-test took place and at the same order of days.

\section{Study Variables:}

First: the independent variable:

Training program using small-sided games.

Second: The Dependent Variable:

The level of skill performance.

\section{Statistical Treatment:}

1. "t-test" for the associated samples to reveal differences between the pre and post application of the study tests and according to each of the study groups.

2. The use of the "t-test" on independent samples to detect the existence of differences between members 
of the two groups in the post application, as well as to verify the parity of the groups in the pre-application. Arithmetic averages and standard deviations were also extracted to describe the level of performance according to each group.

3. Pearson correlation coefficient between the two application times to verify the stability of the study tests.

4. The ETA square to calculate the effect size.

\section{Presentation and Discussion of Results}

\section{The first hypothesis, which was stated:}

There are statistically significant differences at the level of significance $(\alpha \leq 0.05)$ between the pre and post measurements of the effect of using small-sided games on developing the level of skill performance and in favor of the post measurement for students of an advanced football course at Mutah University?

To test the validity of this hypothesis, a "t-test" was conducted for the related samples (paired samples Statistics) in order to reveal the differences between the pre and post measurement of the skill level of the students of an advanced football course at the University of Mutah within the group that used the small-sided games, and Table 4. illustrate the results.

The data in Table 4. show that there are statistically significant differences at the level of significance $(\alpha \leq 0.05)$ between the pre and post measurements of the level of skill performance represented in the following skills (feeling and controlling the ball, running with the ball, passing, dribbling, and shooting) in the experimental group. The small-sided games were used in terms of the value of $t$ and the level of significance associated with it. The size of the calculated effect values ranged between $(85.12 \%-92.23 \%)$, which confirms the existence of a significant effect of using the small-sided games on developing the level of skillful performance of the beginners of football.

\section{The second hypothesis, which was stated:}

There are statistically significant differences at the level of significance $(\alpha \leq 0.05)$ between the pre and post measurements of the effect of regular training on developing the level of skill performance and in favor of the post measurement for students of an advanced football course at Mutah University?

To test the validity of this hypothesis, a "t-test" was conducted on the related samples (paired samples Statistics) to reveal the differences between the pre and post measurement and the level of skill performance of the students of an advanced football course at the University of Mutah within the group that used regular training, and Table 5. Explain the results.

The data in Table 5. reveal the presence of statistically significant differences at the level of significance $(0.05 \alpha \leq)$ between the pre and post measurements of the level of skill performance of the group that used the standard training in terms of the value of $t$ and the level of significance associated with it. The size of the calculated effect values ranged between $(42.60 \%-81.72 \%)$ which confirm the significant effect of using regular training on developing the level of skill performance of students of an advanced football course at Mutah University. 
Table 4. "t-test" for related samples to detect differences between the pre and post measurements of skill performance level of the experimental group that used the small-sided games. (N=14)

\begin{tabular}{|c|c|c|c|c|c|c|c|c|c|}
\hline Football skills & Test & Measure unit & Application & arithmetic mean & standard deviation & Freedom degree & T value & Statistical significance & Effect size \\
\hline \multirow{2}{*}{$\begin{array}{l}\text { Feeling and } \\
\text { control the ball }\end{array}$} & \multirow{2}{*}{ Dribbling the ball } & \multirow{2}{*}{ Repetition } & Pre & 53.61 & 12.60 & \multirow{2}{*}{13} & \multirow{2}{*}{8.43} & \multirow{2}{*}{$000^{*}$} & \multirow{2}{*}{$85.12 \%$} \\
\hline & & & Post & 71.50 & 9.30 & & & & \\
\hline \multirow{2}{*}{$\begin{array}{l}\text { Running with the } \\
\text { ball }\end{array}$} & \multirow{2}{*}{$\begin{array}{l}\text { Running with the } \\
\text { ball } 30 \mathrm{~m}\end{array}$} & \multirow{2}{*}{ Time/s } & Pre & 8.56 & 0.36 & \multirow{2}{*}{13} & \multirow{2}{*}{14.22} & \multirow{2}{*}{$000^{*}$} & \multirow{2}{*}{$88.42 \%$} \\
\hline & & & Post & 7.49 & 0.50 & & & & \\
\hline \multirow{2}{*}{ Passing } & \multirow{2}{*}{$\begin{array}{l}\text { Passing accuracy } \\
\text { test } 4 \text { goals }\end{array}$} & \multirow{2}{*}{ Degree } & Pre & 1.36 & 1.26 & \multirow{2}{*}{13} & \multirow{2}{*}{8.73} & \multirow{2}{*}{$000^{*}$} & \multirow{2}{*}{$92.23 \%$} \\
\hline & & & Post & 3.47 & 0.76 & & & & \\
\hline \multirow{2}{*}{ Dribbling } & \multirow{2}{*}{ Slalom Run $25 \mathrm{~m}$} & \multirow{2}{*}{ Time/s } & Pre & 12.02 & 0.72 & \multirow{2}{*}{13} & \multirow{2}{*}{9.20} & \multirow{2}{*}{$000^{*}$} & \multirow{2}{*}{$90.80 \%$} \\
\hline & & & Post & 9.90 & 2.46 & & & & \\
\hline \multirow{2}{*}{ Shooting } & \multirow{2}{*}{$\begin{array}{l}\text { Shooting the ball } \\
\text { from } 5 \text { sections }\end{array}$} & \multirow{2}{*}{ Degree } & Pre & 2.32 & 0.59 & \multirow{2}{*}{13} & \multirow{2}{*}{10.89} & \multirow{2}{*}{$000^{*}$} & \multirow{2}{*}{$91.02 \%$} \\
\hline & & & Post & 4.34 & 0.43 & & & & \\
\hline
\end{tabular}

*Statistical function at the level of significance $(\alpha \leq 0.05)$

Table 5. "t-test" for related samples to detect differences between the pre and post measurements of skill level of the group that used the standard training ( $\mathrm{N}=14$ )

\begin{tabular}{|c|c|c|c|c|c|c|c|c|c|}
\hline Football skills & Test & Measure unit & Application & arithmetic mean & standard deviation & Freedom degree & T value & Statistical significance & Effect size \\
\hline \multirow{2}{*}{$\begin{array}{l}\text { Feeling and } \\
\text { control the ball }\end{array}$} & \multirow{2}{*}{ Dribbling the ball } & \multirow{2}{*}{ Repetition } & Pre & 52.10 & 9.78 & \multirow{2}{*}{13} & \multirow{2}{*}{7.25} & \multirow{2}{*}{$000^{*}$} & \multirow{2}{*}{$81.72 \%$} \\
\hline & & & Post & 65.40 & 7.63 & & & & \\
\hline \multirow{2}{*}{$\begin{array}{l}\text { Running with the } \\
\text { ball }\end{array}$} & \multirow{2}{*}{$\begin{array}{l}\text { Running with the } \\
\text { ball } 30 \mathrm{~m}\end{array}$} & \multirow{2}{*}{ Time/s } & Pre & 8.75 & 1.11 & \multirow{2}{*}{13} & \multirow{2}{*}{5.34} & \multirow{2}{*}{$000^{*}$} & \multirow{2}{*}{$65.90 \%$} \\
\hline & & & Post & 7.94 & 0.54 & & & & \\
\hline \multirow{2}{*}{ Passing } & \multirow{2}{*}{$\begin{array}{l}\text { Passing accuracy } \\
\text { test } 4 \text { goals }\end{array}$} & \multirow{2}{*}{ Degree } & Pre & 1.52 & 1.56 & \multirow{2}{*}{13} & \multirow{2}{*}{3.34} & \multirow{2}{*}{$000^{*}$} & \multirow{2}{*}{$56.78 \%$} \\
\hline & & & Post & 2.41 & 2.81 & & & & \\
\hline \multirow{2}{*}{ Dribbling } & \multirow{2}{*}{ Slalom Run $25 \mathrm{~m}$} & \multirow{2}{*}{ Time/s } & Pre & 12.13 & 0.73 & \multirow{2}{*}{13} & \multirow{2}{*}{2.90} & \multirow{2}{*}{$000 *$} & \multirow{2}{*}{$42.60 \%$} \\
\hline & & & Post & 10.78 & 0.55 & & & & \\
\hline \multirow{2}{*}{ Shooting } & \multirow{2}{*}{$\begin{array}{l}\text { Shooting the ball } \\
\text { from } 5 \text { sections }\end{array}$} & \multirow{2}{*}{ Degree } & Pre & 2.45 & 0.84 & \multirow{2}{*}{13} & \multirow{2}{*}{4.56} & \multirow{2}{*}{$000^{*}$} & \multirow{2}{*}{$63.50 \%$} \\
\hline & & & Post & 3.09 & 0.42 & & & & \\
\hline
\end{tabular}

*Statistical function at the level of significance $(\alpha \leq 0.05)$

Table 6. "t-test" of independent samples to detect differences between groups in the post measurement for the level of skillful performance ( $N=28)$

\begin{tabular}{|c|c|c|c|c|c|c|c|c|c|}
\hline Football skills & Test & Measure unit & Application & arithmetic mean & standard deviation & Freedom degree & T value & Statistical significance & Effect size \\
\hline \multirow{2}{*}{$\begin{array}{l}\text { Feeling and } \\
\text { control the ball }\end{array}$} & \multirow{2}{*}{ Dribbling the ball } & \multirow{2}{*}{ Repetition } & Experimental & 71.50 & 9.30 & \multirow{2}{*}{26} & \multirow{2}{*}{2.65} & \multirow{2}{*}{$* 000$} & \multirow{2}{*}{$27.70 \%$} \\
\hline & & & Control & 65.40 & 7.63 & & & & \\
\hline \multirow{2}{*}{$\begin{array}{l}\text { Running with the } \\
\text { ball }\end{array}$} & \multirow{2}{*}{$\begin{array}{l}\text { Running with the } \\
\text { ball } 30 \mathrm{~m}\end{array}$} & \multirow{2}{*}{ Time/s } & Experimental & 7.49 & 0.50 & \multirow{2}{*}{26} & \multirow{2}{*}{3.57} & \multirow{2}{*}{$* 000$} & \multirow{2}{*}{$35.70 \%$} \\
\hline & & & Control & 7.94 & 0.54 & & & & \\
\hline \multirow{2}{*}{ Passing } & \multirow{2}{*}{$\begin{array}{l}\text { Passing accuracy } \\
\text { test } 4 \text { goals }\end{array}$} & \multirow{2}{*}{ Degree } & Experimental & 3.47 & 0.76 & \multirow{2}{*}{26} & \multirow{2}{*}{5.63} & \multirow{2}{*}{$* 000$} & \multirow{2}{*}{$52.90 \%$} \\
\hline & & & Control & 2.41 & 2.81 & & & & \\
\hline \multirow{2}{*}{ Dribbling } & \multirow{2}{*}{ Slalom Run 25m } & \multirow{2}{*}{ Time/s } & Experimental & 9.90 & 2.46 & \multirow{2}{*}{26} & \multirow{2}{*}{4.05} & \multirow{2}{*}{$* 000$} & \multirow{2}{*}{$37.60 \%$} \\
\hline & & & Control & 10.78 & 0.55 & & & & \\
\hline \multirow{2}{*}{ Shooting } & \multirow{2}{*}{$\begin{array}{l}\text { Shooting the ball } \\
\text { from } 5 \text { sections }\end{array}$} & \multirow{2}{*}{ Degree } & Experimental & 4.34 & 0.43 & \multirow{2}{*}{26} & \multirow{2}{*}{6.17} & \multirow{2}{*}{$* 000$} & \multirow{2}{*}{$56.90 \%$} \\
\hline & & & Control & 3.09 & 0.42 & & & & \\
\hline
\end{tabular}

*Statistical function at the level of significance $(\alpha \leq 0.05)$ 


\section{To test the validity of the third hypothesis, which read:}

There are statistically significant differences at the significance level $(\alpha \leq 0.05)$ in the post-measurement between the use of small-sided games and the regular training on developing the level of skill performance of students of an advanced football course at Mutah University?

A "t-test" was conducted on the independent samples (Independent Samples Statistics) to reveal the differences in the post measurement of the skill level of the beginners of football according to the group variable (training using small-sided games, regular training), and Table 6 . illustrates the results.

The data in Table 6. reveal the existence of statistically significant differences at the level of significance $(\alpha \leq 0.05)$ between the two groups in the post measurement of the level of skill performance in (feeling and controlling the ball, running with the ball, passing, dribbling, and shooting). For the value of (T) and the level of the accompanying significance, and by referring to the arithmetic averages, it appears that the differences were in the favor of the experimental group, and the calculated effect values ranged between $(27.70 \%-56.90 \%)$. Table 6 also indicate the presence of a significant impact of using mini-side games on developing the level of skill performance of students of an advanced football course at Mutah University.

\section{Discussing the first hypothesis}

The researcher attributes this development to the effectiveness of using small-sided games and their systematic performance in accordance with the requirements of advanced football course students. Plus, the variety of exercises that are similar to the atmosphere of the competitive match, and the performance of small-sided matches and interconnected exercises designed to develop the side of skill performance. Also, the complete commitment to the vocabulary of the training units and the good distribution of the components of the training load, which reflected positively on the development of skill performance. In addition to their performance and repetition under various circumstances and ways. Nevertheless, the working in balance between the individual performance of the players, the training models prepared in mini-matches that are performed under the conditions of the game and competitive situations which are similar to the conditions of the match and under the pressure of the players of the opposing team and sufficient time given to perform the skill individually and linking it to group performance. Abdul Razzaq (2013) emphasized that the small-sided games are small games in which what happens exactly during matches creates a kind of adaptation and good behavior for the player when repeating the same situation. Theis result is agreed by the study of Taha and Jalal (2019), who indicated that the small-sided games positively affected the development of basic football skills among football beginners (11-12) years old. It was also confirmed by the study of Hijab (2019), which confirmed that the small-sided games positively affected the development of basic skills for football players less than (17) years old. It also goes with the study of El-Araby, Kaddour, and Mustafa (2018) that the small-sided games positively affected the development of the speed of the motor response and some basic skills of football players (17-19) years old. Moreover, the study of Yassin (2016) revealed that that the small-sided games had a positive effect on developing the basic skills of football players in the school category (6-9 years), which was approved by the study of Hussein and Hisham (2014), which indicated that the small-sided games positively affected the development of some basic skills among football players of (14-16) years. Also agreed with the study of Katis and Kellis (2009), which indicated that the small-sided games have positively affected the development of the physical abilities and basic skills of football players.

\section{Discussing the second hypothesis}

The researcher attributes the development of this group to applying the regular program for a period of (8) weeks, which was distinguished by its suitability for students of an advanced football course in terms of intensity, repetitions, comfort between exercises and comfort between groups. In addition to the use of exercises, methods and tools in each training unit As the training program stimulated the students to challenge and compete, the researcher stressed on the attendance of students of the advanced football course and stressed on the full commitment to all the required duties. In addition to the regular training exercises that were distinguished by being divers, incremental and interesting. These exercises bring suspense and challenge opportunity for all students to train and compete together. What confirms this result is the size of the calculated effect, which indicates, according to Cohen's classification, the existence of a significant impact of the regular training program. This result was in agreement with the study of Hussain (2018), which indicated that the regular training program had a positive effect on the development of the skills and physical characteristics of football players under (23) years old. It is also agreed by the study of Hisham and Zakaria (2017), which indicated that regular training had a positive effect on the development of physical and motor characteristics and some basic skills among young footballers. This result goes with Bodbos (2015) study which indicated that regular training has a positive effect on the development of motor abilities and basic skills among football players. However, the study of Katis and Kellis (2009), which indicated that regular training had a positive effect on the development of the physical abilities and basic skills of football players, and it agreed with the 
study of Abdul Razzaq (2013), which specified that regular training had a positive effect on the development of some special physical abilities and skills of football players. It is also approved by the study of Bin Dhahabia (2013), which indicated that regular training had a positive effect on the development of some physical abilities and basic skills of football players from (13-15) years, and by the study of (Radziminski, 2013), which asserted that the regular training program had an effect positively on the development of some physical and skill abilities of football players under 16 years of age, and goes by the study (Dellal et.al. 2011), which showed that regular training has a positive effect on the development of some skill and physical abilities of soccer players.

\section{Discussing the third hypothesis}

The researcher attributes the existence of differences in skill tests to the advantage of the training program used by designing exercises, according to the style of small-sided games in developing basic skills in football, compared to the traditional training used by the coach and applied to members of the control group. The exercises were practiced on a small scale and with different numbers. However, it is considered as one of the important methods in developing these skills especially for football team. And if the coach is able to bypass the usual methods inside the middle, he will increase the training stimuli. So, he can stimulate the players, thus breaking the boredom and allocating part of the training to perform various exercises. Adding to that the side mini games are a method or system that uses different movements to simultaneously solve the motor and technical duty together. Training serves more than one athlete's side, which gives the player the opportunity to participate effectively in the game and always being close to playing direct situations. It enables the player to score more, and increases the percentage of touching the ball of $(50 \%)$ or more from traditional play $(11 \mathrm{v} 11)$ and the stoppage rate decreases to $(8 \%)$ less than traditional play, which reaches (34\%) and the percentage of individual positions increases (1v1) four times more than tradition game play. These results are in agreement with the study of Al-Sayeh and Abdel-Moneim (2006), which indicated that the differences of developments in favor of the individuals of the experimental group were due to the application of the suggested exercises using the method of small-sided games. As it enhances the effective repetition on the level of skill performance and individuals practice models of multiple motor skills with repetition without boredom. The different situations within the game give the participants opportunities to interact with each other. This is also agreed by the results of the Taha and Jalal
(2019) study, which indicated that there are statistically significant differences at a significance level $(\alpha \leq 0.05)$ between groups in the post-measurement and in favor of the experimental group in all skill variables, namely (Passing, shooting, running with the ball, controlling the ball) for football beginners (11-12) years old. It is also approved by Hijab study (2019), which showed that the small-sided games applied to the experimental group have a positive effect on improving the results of the post-tests better than the control group in all skill variables (ball control, running with the ball, passing and receiving, and kicking the ball) for football players less than (17) years old. Al-Arabi et al. (2018) Also agreed with the results, which indicated that the small-sided games that were applied to the experimental group have a positive effect in improving the results of the physical post-tests and is better than the control group in the speed of movement response and some basic skills (running with the ball, passing, and shooting) among Football players (17-19) years old. Plus, it goes with the results of Yaseen (2016) study, which indicated that the side mini-games positively affected the development of basic skills (passing the ball and shooting) of school football players of (6-9 years). And it also goes with the results of Hussein and Hisham (2014), which revealed that the small-sided games positively affected some basic skills (passing accuracy, shooting accuracy and reception accuracy) of football players of (14-16) years old, and agreed with the results of Ben Dhahabia's study (2013), which indicated that the small-sided games affected Positively some physical abilities and basic skills (passing, shooting, receiving) of football players of (13-15) years old.

\section{Conclusions}

In light of the objectives of the study and by presenting and discussing the results, the researcher reached the following conclusion:

1. The training program using small-sided games for a period of (8) weeks has a positive on developing the skill level of students of an advanced football course at Mutah University better than the regular training.

2. All soccer skills showed a remarkable development, as the skill of shooting came first $(56.90 \%)$, then passing $(52.90 \%)$ in the second place, and dribbling came in the third place at $(37.60 \%)$, where running with the ball came fourth (35.70\%), and feeling and controlling the ball came in the fifth place of $(27.70 \%)$. 


\section{Recommendations}

Based on the results and the conclusion presented, the researcher recommends the following:

1. Taking advantage of the small-sided games program to develop the level of skill performance of students in football courses at all departments and colleges of the Physical Education and for both genders in Jordan.

2. Conducting courses and workshops by the competent authorities such as the Jordanian Football Association, Jordanian universities and the Ministry of Education for coaches and teachers in order to integrate mini-games and including it in the school and university curricula.

3. Focus on that specific age in the beginning by determining an organized program which is suitable with their physical levels and skills in a scientific way gradually.

\section{Sample Appendix for the Training Module}

$\underline{\text { The Goals (Dribbling, passing, shooting) }}$

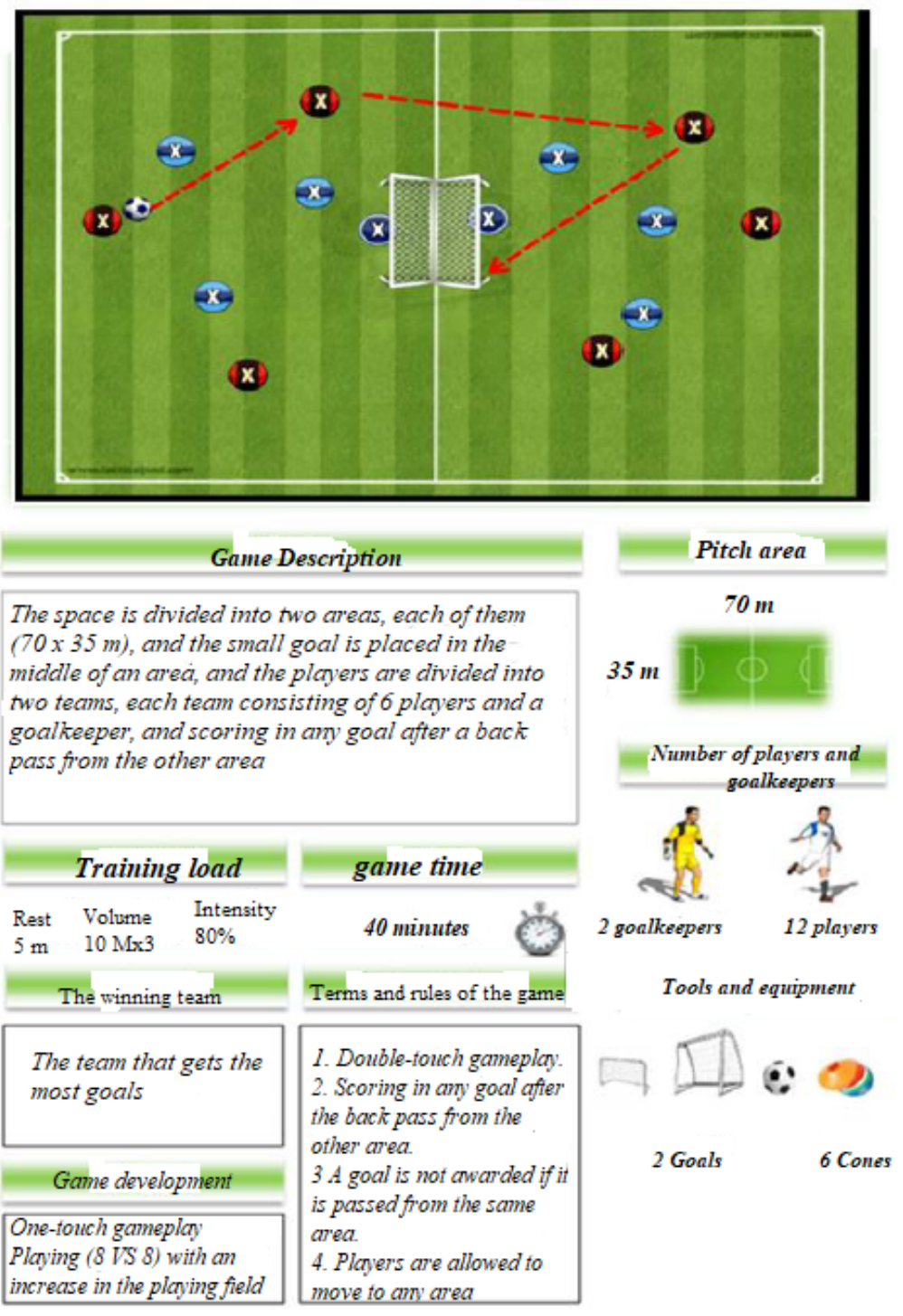




\section{REFERENCES}

[1] Al-Khatib, M, The Effect of Programs Based on Manual Resistance with Weights on Developing Muscular Strength and Skill Level of Emerging Football Players, Unpublished Master Thesis, College of Physical Education, University of Jordan, Jordan, 2010.

[2] Tchokonte. S. Football development and its consequences on training and physical preparation. studying the effect of mini-games on adaptation Players, Ph.D. University, University of Strasbourg. université de Strasbourg, 2011.

[3] Dellal. A. Logo. C. Wong. D. \& Chamari. K, Effect of the number of ball contacts within bouts of 4 vs. 4 small - sided soccer gameInternational Journal of Sports Physiology and Performance, ( 3 ) 6 .322-333, 2011.

[4] Chebbi . M, "utilisation de la méthode de perceptionde l'effort Conséquences dans l'Orientation de l'Entrainement ,Application Spécifique aux Exercices Intermittents course à Haute Intensité et aux Jeux Réduits. Thèse Doctorat. Université Strasbourg. De Boeck, 2016.

[5] Hill-Haas. S., Dawson. B., Impellizzeri. F., Coutts. A., Physiology of Small-Sided Games Training in Football, Sports Medicine. 41. 199-220. 2011.

[6] Dellal . D. Christophe. V., Adam. O., Erica. N. \& Vincent. P., Small-Sided Game Versus Interval Training In Amateur Soccer Players : Effects On The Aerobic Capacity and The Ability to Perform Intermittent exercises with changes of direction .The Journal of Strength and Conditioning Research the TM . 26 (10) . 2712-2720, 2012.

[7] Owen. A., Twist. C., \& Ford F., Small-sided games: The physiological and technical effect of altering pitch size and player numbers. Insight. 7. 50-53, 2004.

[8] Katis. A. and Kellis. E., Effects of small-sided games on physical conditioning and performance in young soccer players. Journal of Sports Science and Medicine. 8. 374-380, 2009.

[9] Taha, H, and Jalal, N., Studying the effect of mini-side games in developing some basic skills for football players of (11-12) years old, the Seventh International Conference on Sport and its Scientific and Practical Applications, Volume (3), College of Physical Education and Sports Sciences, University of Basra, Iraq, 2019.

[10] Hassan, K and Hisham, Gh. Study the extent of the impact of mini-games on the development of some basic football skills among younger (14-16) years old. University of Abdelhamid Ben Badis Mostaganem, Algeria, 2014.

[11] Jones. S.. \& Drust. B., Physiological and technical demands of $4 \mathrm{v} 4$ and $8 \times 8$ games in elite youth soccer players, Kinesiology Journal of Strength and Conditioning Research, 22 (5): 1449-57. (2007).

[12] Yassin, B., The Impact of a Proposed Training Program for Small Games on the Development of Some Basic Skills in Football for Schools Category (6-9) Years, Scientific Journal of the Laboratory of Physical Activity Sciences and Techniques, Issue 8, University of Djelfa, Algeria, 2016.

[13] Dellal. A., Chamari K., Pintus. A., Girard. O., Cotte. T., \& Keller. D., Heart Rate Responses During Small-Sided Games and Short Intermittent Running Training in Elite Soccer Players: A Comparative Study, Journal of Strength and Conditioning Research, 1457-1449 .(5)22. 2008.

[14] Little. T., Optimizing the use of soccer drills for physiological development, Strength Conditioning Journal. 31. 67-74, 2009

[15] Abu Abdo, H., The Skills Preparedness for Football Players, Al-Radaa Artistic Library and Printing Press, 1st Edition, Alexandria, Egypt, 2007.

[16] Abdel-Razek, K, The effect of playing training exercises in different areas on the development of some physical abilities and skill performance in football, Scientific Journal of the Laboratory of All and Techniques of Physical Activity in Sports, No. 8, University of Algeria, 2013.

[17] Hijab, E., The Effectiveness of Training Using Mini-Games in Developing Basic Skills for Football Players Under 17 Years of Age, Scientific Journal of Technological Sciences for Physical Activities and Sports Volume 16 Issue $2 \mathrm{pp}$. $45-65,2019$.

[18] Al-Arabi, M, Kadour B, and Mustafa A., The effectiveness of Small-games on developing the speed of the motor response and the nature of its relationship to developing the skillful performance of young football The Researcher Journal in Human and Social Sciences, Issue 35, Algeria, 2018.

[19] Hussein, A., The effect of using mini-games (5v5) and (2v2) on developing some physical and skill traits of football players. Unpublished $\mathrm{PhD}$ thesis, Muhammad Khudair University. Soukra. Algeria, 2018.

[20] Hisham, A. and Zakaria, S., The impact of a proposed training program in mini-games to develop some physical elements (speed and coordination) and some basic skills (dribbling and reception) among soccer players the junior class of the Shawiya Federation team, Institute of Science and Technology of Physical Activities and Sports, University Al-Arabi Bin Mahidi, Oum El-Bouaghi, Algeria, 2017.

[21] Bodbos, M., The effect of mini-games on developing agility and improving dribbling skills. Unpublished MA thesis, Elaraby Ben Mahdi University, Oum El Bouaghi, Algeria, 2015.

[22] Ben Dehiba, J, The effect of using mini-court training on improving the physical and skills aspects of football players participating in school sports teams Scientific Journal of Science and Technology of Physical and Sports Activities 10, University of Abdelhamid Ben Badis Mostaganem Institute of Physical Education and Sports, 120-137, 2013.

[23] Radziminski. L., Comparison of the Physiological and Technical Effects of High-Intensity Running and Small-Sided Games in Young Soccer Players. International Journal of Sports Science \& Coaching. 8(3): 455-465, 2013.

[24] Al-Sayeh, M, Abdel-Moneim, M , Small games and their applications, Dar Al-Wafa for the World of Printing and Publishing, 1st Edition, Alexandria, Egypt, 2006. 